\title{
Long-term time series and activity size distribution of beryllium-7 in the atmospheric environment time series and activity size distribution of iodine-131 in Austria after the Fukushima NPP accident
}

\author{
W. Ringer, J. Klimstein and M. Bernreiter \\ Competence Centre for Radioecology and Radon (CC-RARA), Austrian Agency for Health \\ and Food Safety (AGES), Wieningerstrasse 8, 4020 Linz, Austria
}

\begin{abstract}
In the framework of the Austrian federal monitoring programme of the environment and food stuffs radioactivity in air has been measured for many years. High volume aerosol samplers at different locations in Austria collect aerosols on filter material. After a sampling period of one week the filters are measured routinely with high resolution gamma spectrometry. One sampler is located at a high-altitude Alpine station at $3106 \mathrm{~m}$. In addition, a high volume cascade impactor with six impactor stages (Dp, 50 cut-points at 10.2, 4.2, 2.1, 1.4, 0.73, $0.41 \mu \mathrm{m}$, and backup filter) is in operation at the sampling site in Linz. Damaged by a tsunami, from 12 March 2011 on radionuclides have been released by the Fukushima nuclear power plant (Japan) into the atmosphere and the sea. Contaminated air masses were transported across the Pacific and North America to Europe and were detected by the national monitoring network in Austria as well as in many other countries. In this poster we present the long-term time series and activity size distribution of Be-7 in air. Because of its actuality the time series of gaseous and particulate fraction and the activity size distribution of I-131 in Austria after the Fukushima NPP accident on 11 March 2011 are given.
\end{abstract}

\section{RESULTS AND DISCUSSION}

The cosmogenic radionuclide Be-7 is formed through spallation reactions with decreasing production rates with atmospheric depth. Although about two thirds of the Be-7 production takes place in the stratosphere and one third in the troposphere (mainly in the upper troposphere), due to stratosphereto-troposphere exchange (STE) Be-7 is also present in the near-to-ground atmosphere. Factors controlling its activity levels are wet scavenging, STE, downward transfer in the troposphere and horizontal transfer from middle and subtropical latitudes to higher latitudes [1, 2].

Figure 1 shows the time series of Be-7 and Cs-137 over a period of 24 years. A clear seasonal trend can be seen with maximum Be-7 activity concentrations in summer and minimum in winter due to stronger STE processes in the summer period. Furthermore, this seasonal variation is superposed by the 11-year cycle of solar activity which influences the production rate of $\mathrm{Be}-7$ in the upper atmosphere. In contrast, the seasonal variation of Cs- 137 shows a maximum in winter and a minimum in summer as the dominant process is resuspension and stable weather conditions (inversion) are frequent in the winter period.

As various factors govern the Be-7 activity concentration in the near-to-ground atmosphere they are highly episodic and vary strongly. This is well demonstrated in Figure 2 where the Be-7 results are given per day of the year from the high-altitude station at Sonnblick $(3106 \mathrm{~m})$ for a period of 15 years. Due to the relatively short sampling interval of one day this data is a valuable input when studying stratospheric intrusions [3]. 


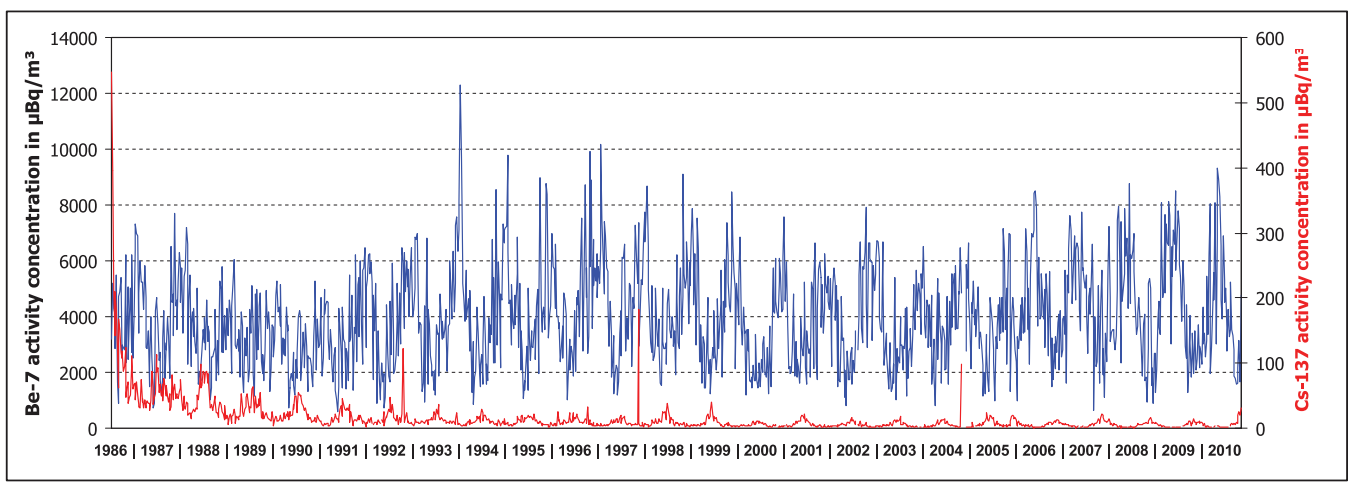

Figure 1. Time series of Be-7 (upper line) and Cs-137 (lower line) in the near-to-ground atmosphere in Klagenfurt (Austria) from August 1986 to December 2010.

Regarding the Be-7 activity size distribution in near-to-ground air (see Figure 3) around $90 \%$ of the total Be-7 activity is associated with particles smaller than $1.4 \mu \mathrm{m}$ in all seasons. The activity size distributions give a quite similar picture for spring, autumn, and winter whereas in summer a strong shift to particles smaller than $0.41 \mu \mathrm{m}$ can be seen. For $\mathrm{Pb}-210$ the same pattern has been observed.

In Figure 4 the time series of particulate and gaseous I-131 in Linz (Austria) are given. The highest activity concentrations were detected from 29 to 31 March 2011 which can be related to the main emission into the atmosphere by the damaged Fukushima NPP which occured on 15 March 2011. The ratio of gaseous to particulate iodine was not constant but varied in the range of 1.0 to 4.4.

Finally, the activity size distribution shows for I-131 a more steady slope as for Be-7 (Figure 5). Nevertheless, most I-131 is attached to the smaller and thus inhalable particles.

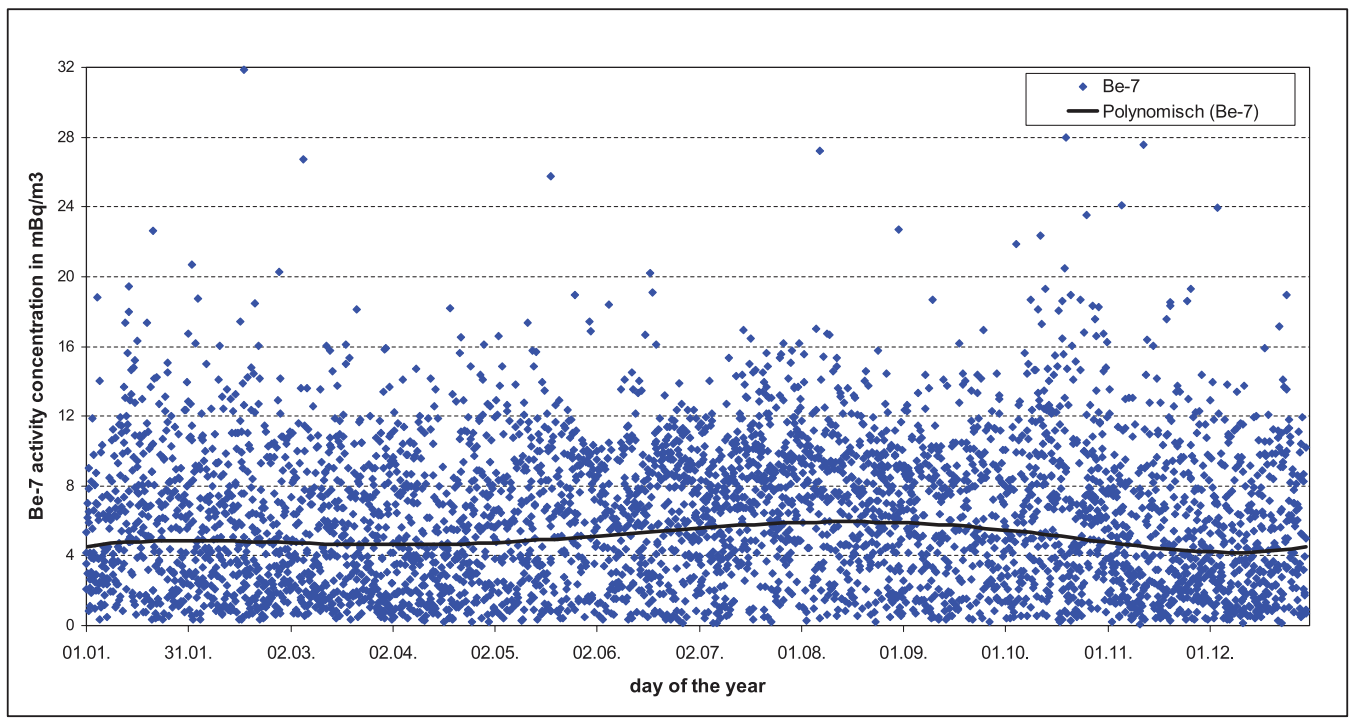

Figure 2. Be-7 results in air per day of the year from a high-altitude station in Austria (Sonnblick, $3106 \mathrm{~m}$ ) for the period July 1996 to December 2010. 


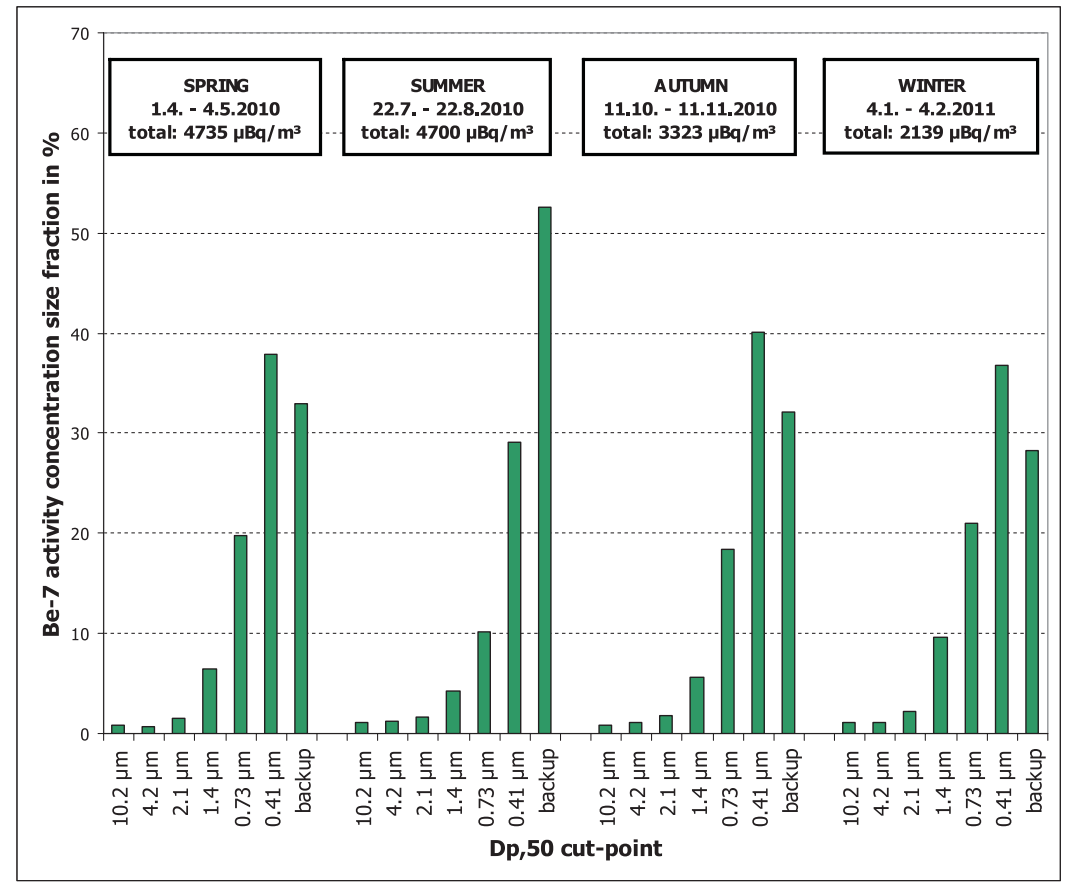

Figure 3. Be-7 activity size distribution in the near-to-ground atmosphere in Linz (Austria).

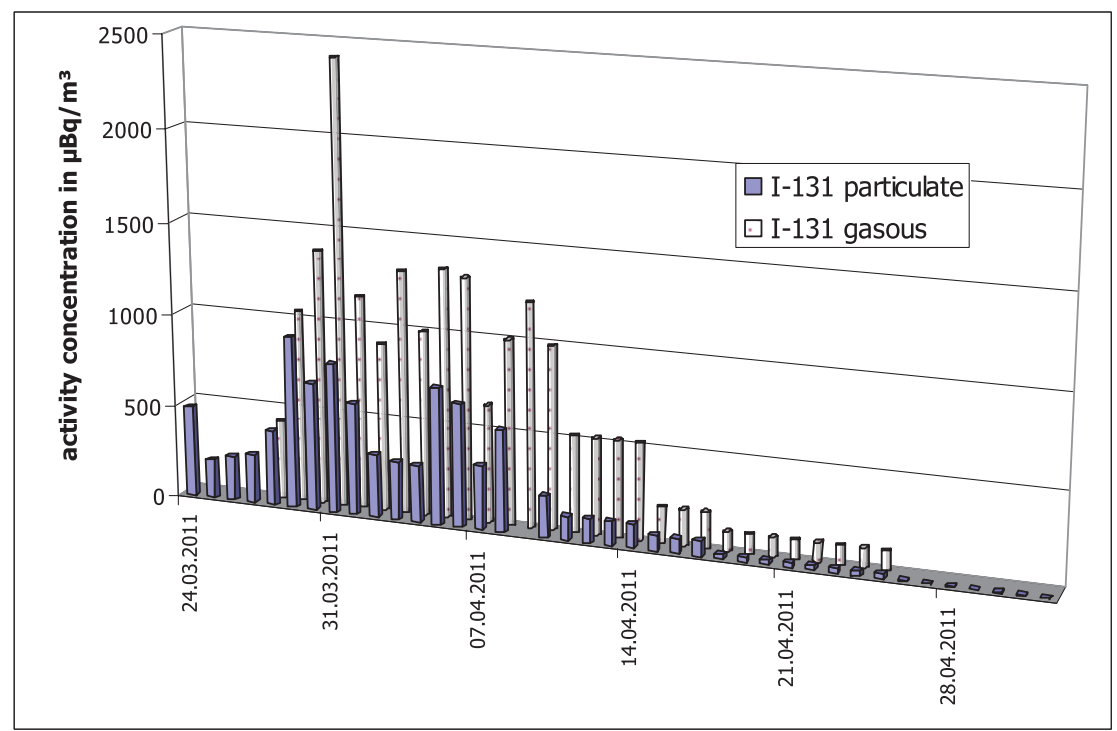

Figure 4. Gaseous and particulate I-131 in the near-to-ground atmosphere in Linz (Austria) after the Fukushima NPP accident. 

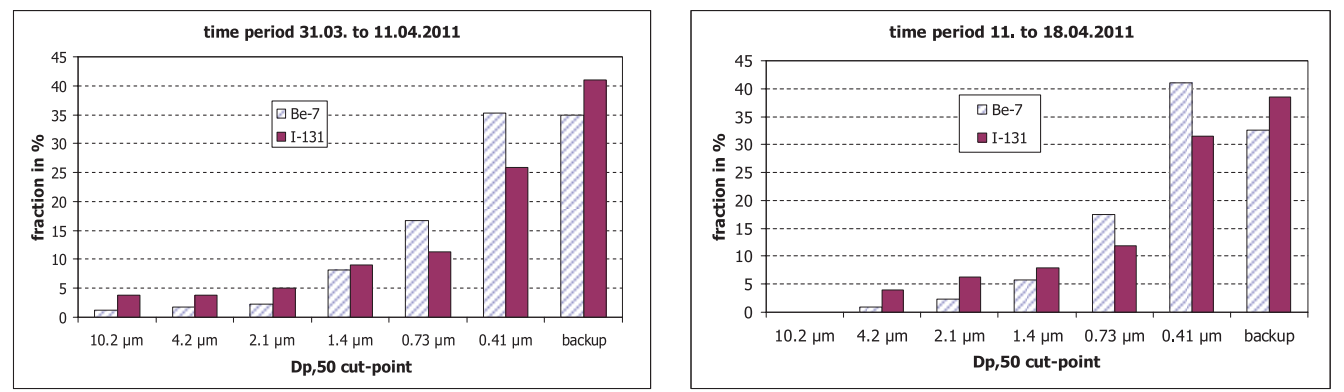

Figure 5. Be-7 and I-131 activity size distributions in the near-to-ground atmosphere in Linz (Austria) after the Fukushima NPP accident for two sampling intervals.

\section{References}

[1] Gerasopoulos E. et al, Atmospheric Environment 35, 6347-6360 (2001)

[2] Gerasopoulos E. et al, Radioactivity in the Environment, Volume 7: The Natural Radiation Environment VII, 863-870 (2005)

[3] Stohl A. et al, Atmospheric Environment 34, 1323-1354 (2000) 